\title{
Crusted (Norwegian) Scabies and HTLV-1 Infection Association: A Case Report
}

\author{
Bernardo Times de Carvalho ${ }^{1}$, Arthur Arcoverde Perrier ${ }^{2}$, Patrícia Maria Mirelle de Macedo e Silva ${ }^{3}$, João \\ Roberto Cabral da Silva ${ }^{4}$
}

${ }^{1}$ Gastroenterology Department, Universidade de Pernambuco, Recife-Pernambuco, Brazil

${ }^{2}$ Internal Medicine Department, Hospital Maria Lucinda, Recife-Pernambuco, Brazil

${ }^{3}$ Oncology Department, Hospital do Cancer de Pernambuco, Recife-Pernambuco, Brazil

${ }^{4}$ Internal Medicine Department, Hospital Maria Lucinda, Recife-Pernambuco, Brazil

*Corresponding Author: Bernardo Times de Carvalho; b.timesc@gmail.com

Received 27 January 2021;

Accepted 20 February 2021;

Published 01 March 2021

\begin{abstract}
Crusted scabies, formerly known as Norwegian scabies is as uncommon presentation of scabies that may occur in the in association with an immunosuppressive status. The article aims to present a case report in which a male patient with HTLV-1 carrier status admitted for investigation of eczematous and crusted chronic skin lesions and submitted to a dermatologic evaluation and a skin biopsy considering the hypothesis of a cutaneous form of lymphoma associated with HTLV-1 infection had the diagnosis of Crusted scabies instead. There is data regarding de association of crusted scabies and Human T-lymphotropic virus type 1 (HTLV-1) chronic infection. Therefore, this important diagnosis should always be accessed specially in HTLV-1 endemic regions.
\end{abstract}

Keywords: Crusted scabies; Norwegian scabies; Human T-lymphotropic virus type 1; HTLV-1

\section{Introduction}

Human T-lymphotropic virus type 1 is a type $\mathrm{C}$ retrovirus belonging to the Retroviridae family. It is an endemic infection in Japan, South and Central Americas, Middle East and some regions of Africa and Australia. It was the first human oncogenic retrovirus described on 1980. Recent estimation suggests that nearly 20 million people worldwide have been infected ${ }^{[1,2]}$. Transmission could occur by breastfeeding, transplacental, during labor, blood products transfusion, infected needles and sexually. The virus has a tropism to CD4 lymphocytes and the infection has its diagnosis done by serologic procedures such as ELISA and Western Blot technics ${ }^{[1-5]}$.

The HTLV-1 infection can evolve to tropical spastic paraparesis and lymphoma/leukemia of T cells. However, since the infection could induce an immunosuppressive status,opportunistic diseases should have its occurrence also considered ${ }^{[1]}$. Crusted scabies, formerly known as Norwegian scabies is as uncommon presentation of scabies that may occur in the in association with an immunosuppressive status ${ }^{[6]}$. There is data regarding de association of crusted scabies and HTLV-1 chronic infection ${ }^{[4]}$. Therefore, this important diagnosis should always be accessed specially in HTLV-1 endemic regions.

The article aims to present a case report in which a male patient with HTLV-1 carrier status admitted at the hospital for clinical investigation of eczematous and crusted chronic skin lesions, whichwas found to be caused by Crusted scabies. This highlights the importance of consider the possibility of chronic HTLV-1 infection in severe forms of scabies.

\section{Case Report}

A 66 year-old male patient was admitted in the hospital with a clinical history of crusted, mild pruritic skin rash especially in the face, scalp, abdomen and extensor faces of limbs for almost one year that worsened 20 days before admission. He had a chronic history of alcohol consumption but denied prescribed or over-thecounter medication, tobacco or illicit drugs use, as well as history of hemotransfusion or prior surgery.

He had the diagnosis of asymptomatic chronic HTLV-1 infection 3 years before when tried to perform a blood donation. His wife also had the diagnosis of HTLV-1 related transverse myelitis at that time. He complained of a $4 \mathrm{Kg}$ weight loss and fever for the past 3 days before admission. Laboratorial tests showed mild leukocytosis with preserved neutrophils and lymphocytes, normal kidney and hepatic function.

Antibiotics were introduced to cover a possible secondary bacterial skin infection, which cause the fever to cease, but without modification of the skin lesions. It was then performed a dermatologic evaluation and a skin biopsy considering the 
hypothesis of a cutaneous form of lymphoma associated with HTLV-1 infection. Eggs and adult forms of Sarcoptes scabiei were found in the skin fragment confirming the diagnosis of Crusted scabies. Based on the diagnosis treatment with ivermectin
$200 \mathrm{mcg} / \mathrm{kg}$ once a day associated with sulfur based body lotion $5 \%$. The patient experienced resolution of the skin lesions within 2 weeks of treatment, being discharged to complete another 2 weeks of treatment on an outpatient setting.

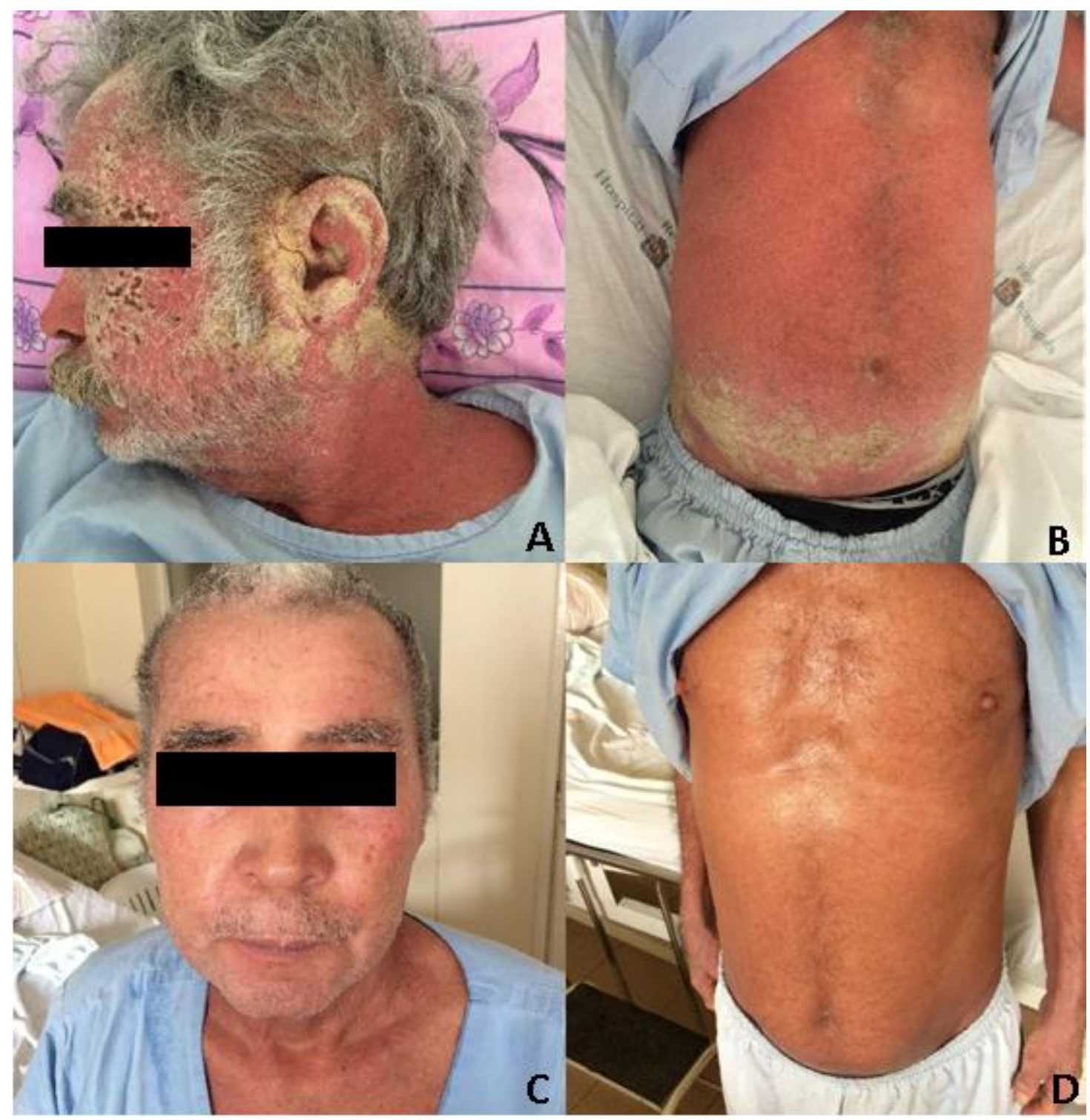

Figure 1: Crusted and exfoliated skin lesions involving face, scalp and trunk (A and B). Regression of lesions after 3 weeks of treatment with ivermectin (C and $\mathrm{D})$.

\section{Discussion}

The CD4 lymphocytes are the main target of HTLV-1, resulting in a chronic infection with a long clinical latency ${ }^{[7]}$. The evidences of greater prevalence, morbidity and mortality of, Pneumocistis jirovecii, fungal and Strongyloides as well as severe forms of dermatologic infections in patients with chronic HTLV-1 infection suggest some degree of immunosuppression ${ }^{[8]}$.

Researches trying to link the HTLV-1 infection to human diseases have been developed since the first description of the virus. Adult $\mathrm{T}$ cells leukemia/lymphoma (ATLL) was the first described condition related to the virus. The role of HTLV-1 was confirmed by demonstration of incorporation of proviral DNA to the neoplastic cells genome ${ }^{[5]}$. An etiologic role of HTLV-1 was further described in a subtype of spastic myelopathy, now known as HTLV-1 associated myelopathy or tropical spastic paraparesis (HAM/TSP) ${ }^{[9]}$. Terada et al in 1992 demonstrated causal association of HTLV-1 with an ophthalmologic involvement known as HTLV-1 associated uveitis ${ }^{[10]}$.

Amano et al described dermatologic lesions in HTLV-1 infected patients, especially those with ATLL or HAM/TSP ${ }^{[1]}$. However, it has been reports of asymptomatic HTLV-1 infected patients as well ${ }^{[11]}$. HTLV-1 infection has been associated with infective dermatitis, $\mathrm{T}$ cell cutaneous lymphoma, leprosy, strogyloides infection and crusted scabies. Some of these conditions have biologic background to justify the association with HTLV-1 infection. Although, the association of HTLV-1 with clinical conditions, such as leprosy, lay on epidemiological database $^{[12]}$.

Verdonck et al had proposed grouping the HTLV-1 associated diseases into three categories (inflammatory, neoplastic and infectious complications) even though the exact pathophysiologic mechanisms were not clearly understood ${ }^{[7]}$. Crusted scabies is among the infectious complications and 
considered a rare severe form of disseminated infestation by the Sarcoptes scabiei var hominis ${ }^{[12]}$.

Boeck and Danielssen first described crusted scabiesin 1848 on Norway in a group of patients with leprosy. It has strong association with low economic levels and before introduction of ivermectin as part of treatment the mortality rate of crusted scabies was around $50 \%$. The natives from north Australia are among the most affected people worldwide ${ }^{[6]}$. Aside from the classic presentation, in which there is less than 20 sarcoptes per gram of skin, there is more than 4000 sarcoptes per gram of skin or about 2 million sarcoptes per person in the crusted scabies. This form of presentation is usually seen in patients with some underlying condition that promote an immunosuppressive state such as HIV infected patients, neoplastic disorders, especially hematologic ones, long term use of corticosteroids and transplant ${ }^{[6,13,14]}$. Secondary infections may occur because the sarcoptes activity in the epidermis can produce skin changes that favor the growth of Staphylococcus and Streptococcus genus bacteria instead of Lactobacillus species ${ }^{[6]}$.

From an immunological point of view, the classical scabies develop a type IV hypersensitivity reaction after four weeks of infestation. The patient who develops crusted scabies has some defect on this form of hypersensitivity reaction, allowing the sarcoptes over proliferation. It means that these patients have an ineffective dermo- epidermal inflammatory response and develop a severe keratodermic reaction with thick yellowish crusts and extremely high parasitic load. Serum immunoglobullins titers of IgE, IgG, IgG1 and IgG4 are marked elevated but are not protective as well as the high eosinophil's count ${ }^{[6,15]}$. Walton et al compared the inflammatory reaction among patients with classic and hyperkeratotic/crusted scabies and concluded that the Norwegian scabies non-protective immunologic response has two main characteristics: a dermo-epidermal cell infiltration with CD8 lymphocyte predomination, instead of CD4 lymphocytes, and a Th2 immune response instead of Th1 ${ }^{[6]}$.

Mounsey et al had demonstrated that those disrupted immune responses in the skin were associated with uncommon local hypersecretion of IL-17. These interleukin is known for your key role at the pathophysiology of psoriasis; it is responsible for an abnormal fast epidermal cells renewal, with epidermal hyperplasia and hyperkeratosis ${ }^{[16]}$. Assuming the IL-17 pathway in the crusted scabies, it would explain the gross aspect of the skin in this presentation of the disease in comparison with the classic scabies. The skin lesions of Norwegian scabies and psoriasis have histological similarities with acantosis, keratinocytes apoptosis, hyperkeratosis, dermal lymphocytic infiltration and basal mitosis. These findings demonstrate a common IL-17 activation pathway pathophysiology ${ }^{[6]}$.

The Norwegian scabies clinically exhibits eritematous plaques, poorly defined that rapidly develops hyperkeratotic psoriasiform scales, crusts, eritrodermia and adenopathy ${ }^{[17]}$. In the disease severe forms, there is more than $30 \%$ of skin involvement, with extension to the scalp. Since there is an abnormal immune response in which CD8 lymphocytes are predominant, patients have mild or even no pruritus, a clinical finding that distinguish the crusted scabies from the classical form known by its intense pruritus especially at night ${ }^{[6]}$. Superimposed bacterial infections and regional lymphadenopathy are frequently found ${ }^{[15]}$.

An early diagnosis of Norwegian scabies is crucial for the disease treatment and control ${ }^{[14]}$. However, a diagnosis delay is the rule as seen on clinical reviews ${ }^{[6]}$. Frequently patients with crusted scabies receive treatment with topical or systemic corticosteroids because of a misdiagnosis with psoriasis, atopic dermatitis or seboreic dermatitis. This would favor the development of severe presentations of the disease ${ }^{[15]}$. The identification of the sarcoptes, its eggs or feces, made by microscopic examination of scales obtained through skin scrapping establishes a definite diagnosis. In some non-satisfactory cases, more sensible and specific methods such as dermatoscopy and videodermatoscopy could be used ${ }^{[18]}$.

The crusted scabies treatment is associated with high rates of resistance and relapses. Ivermectin is the only oral available treatment. It paralyses the sarcoptes by a peripheral neurotoxicity but it does not affect the eggs neither the young sarcoptes. These forms has an incomplete nervous system development, which make it insensible to ivermectin until 2 weeks. As a result single dose treatment is completely ineffective. Australian studies recommend weekly doses of ivermectin for at least 4 consecutive weeks in association with topical treatment such as permetrin, benzyl benzoate and keratolytic lotions as well as environment disinfection and contact isolation ${ }^{[6,15]}$.

Since crusted scabies is a neglected disease, there are few cases reported on medical literature. On the Australian aborigine population in which the HTLV-1 is endemic, Norwegian scabies has been described as a viral infection marker ${ }^{[4,19]}$. Based on this data, a HTLV-1 serologic test in patients with a diagnosis of crusted scabies could be useful on endemic regions, especially when there is no other risk factor for a HTLV-1 infection.

\section{Conclusion}

Although the understanding of HTLV-1 pathophysiology had evolved, it still is an underdiagnosed disease with a great proportion of asymptomatic carriers. The dermatological are present and must be recognized especially in endemic regions. Among those dermatological complications, the crusted scabies, such as this case report, must be included on the differential diagnosis of exfoliative erythrodema in HTLV-1 infected patients.

The dermatological finding of diffuse skin lesions on asymptomatic patients but with positive serology may have relevance on the diagnosis of HTLV-1 infection and on the management of refractory/relapsing lesions to conventional treatment. Thus, screening for HTLV-1 infection is imperative on patients with newly diagnosed Norwegian scabies.

\section{Conflicts of Interests}

All authors declare no conflicts of interests.

\section{References}

[1] Amano M, Setoyama M, Grant A, Kerdel F a. Human Tlymphotropic virus 1 (HTLV-1) infection-dermatological implications. Int $\mathrm{J}$ Dermatol. 2011;50(8):915-20.

[2] Mahieux R, Gessain A. The human HTLV-3 and HTLV4 retroviruses: New members of the HTLV family. Pathol Biol. 2009;57(2):161-6.

[3] Manns A, Wilks RJ, Murphy EL, Haynes G, Figueroa JP, Barnett M, et al. A prospective study of transmission by transfusion of HTLV-I and risk factors associated with seroconversion. Int J cancer [Internet]. 1992 Jul 30 [cited 2018 Jan 14];51(6):886-91. Available from: http://www.ncbi.nlm.nih.gov/pubmed/1639536

[4] Bergman JN, Dodd WAH, Trotter MJ, Oger JJF, Dutz JP. Crusted Scabies in Association with Human T-Cell Lymphotropic Virus 1. J Cutan Med Surg [Internet]. 
1999 Jan 5 [cited 2018 Jan 23];3(3):148-52. Available from:

http://journals.sagepub.com/doi/10.1177/1203475499003 00310

[5] Mahieux R, Gessain A. HTLV-1 and associated adult Tcell leukemia/lymphoma. Rev Clin Exp Hematol [Internet]. 2003 Dec [cited 2018 Jan 14];7(4):336-61. Available from: http://www.ncbi.nlm.nih.gov/pubmed/15129647

[6] Jouret G, Bounemeur R, Presle A, Takin R. La gale hyperkératosique. Ann Dermatol Venereol. 2016;143(4):251-6.

[7] Verdonck K, González E, Van Dooren S, Vandamme AM, Vanham G, Gotuzzo E. Human T-lymphotropic virus 1: recent knowledge about an ancient infection. Lancet Infect Dis [Internet]. 2007 Apr [cited 2018 Jan 14];7(4):266-81. Available from: http://linkinghub.elsevier.com/retrieve/pii/S14733099077 00816

[8] Fernanda M, Grassi R, Médica G, Bahia D, Elizabeth R, Mascarenhas M, et al. Imunossupressão e Infecção pelo HTLV-I. Gaz méd Bahia [Internet]. 2009 [cited 2018 Jan 30];7979(11):56-60. Available from: www.gmbahia.ufba.br

[9] Martinez ARM, Casseb RF, Martins CR, Nucci A, França MC. Sensory neuronopathy heralding human T cell lymphotropic virus type I myelopathy. J Neurovirol [Internet]. 2018 Jan 9 [cited 2018 Jan 14]; Available from: http://www.ncbi.nlm.nih.gov/pubmed/29318453

[10] Terada Y, Kamoi K, Komizo T, Miyata K, Mochizuki M. Human T Cell Leukemia Virus Type 1 and Eye Diseases. J Ocul Pharmacol Ther [Internet]. 2017 May [cited 2018 Jan 14];33(4):216-23. Available from: http://www.ncbi.nlm.nih.gov/pubmed/28263674

[11] DERMATOLOGIC LESIONS IN ASYMPTOMATIC BLOOD DONORS SEROPOSITIVE FOR HUMAN T CELL LYMPHOTROPIC VIRUS TYPE-1. [cited 2018 Jan 14]; Available from: http://citeseerx.ist.psu.edu/viewdoc/download?doi=10.1. 1.523.4916\&rep=rep1\&type $=$ pdf

[12] Sociedade Brasileira de Medicina Tropical. V, Brazil. Superintendência de Campanhas de Saúde Pública. ACM, Proietti FA, Stanciolli E, Martins ML, Serufo JC, et al. Revista da Sociedade Brasileira de Medicina Tropical. [Internet]. Vol. 38, Revista da Sociedade Brasileira de Medicina Tropical. A Sociedade; [cited
2018 Jan 14]. 43-52 p. Available from: http://www.academia.edu/14123298/Lesões_dermatológi cas_em_pacientes_infectado

s_pelo_vírus_linfotrópico_humano_de_células_T_do_tip o_1_HTLV-1_

[13] Scabiei 'nin S, Zamanlı G, Olarak V, Bir G, Sunumu O, Salih Gürel M, et al. A Case Report of Real-Time in vivo Demonstration of Sarcoptes scabiei. 2017 [cited 2018 Jan 19]; Available from: http://turkiyeparazitolderg.org/sayilar/70/buyuk/2292321.pdf

[14] Wong SSY, Woo PCY, Yuen K -y. Unusual Laboratory Findings in a Case of Norwegian Scabies Provided a Clue to Diagnosis. J Clin Microbiol [Internet]. 2005 May 1 [cited 2018 Jan 19];43(5):2542-4. Available from: http://jcm.asm.org/cgi/doi/10.1128/JCM.43.5.25422544.2005

[15] Walton SF, Beroukas D, Roberts-Thomson P, Currie BJ. New insights into disease pathogenesis in crusted (Norwegian) scabies: the skin immune response in crusted scabies. Br J Dermatol [Internet]. 2008 Jun [cited 2018 Jan 21];158(6):1247-55. Available from: http://www.ncbi.nlm.nih.gov/pubmed/18422789

[16] Mounsey KE, Murray HC, Bielefeldt-Ohmann H, Pasay C, Holt DC, Currie BJ, et al. Prospective study in a porcine model of sarcoptes scabiei indicates the association of Th2 and Th17 pathways with the clinical severity of scabies. PLoS Negl Trop Dis [Internet]. 2015 Mar [cited 2018 Jan 21];9(3):e0003498. Available from: http://www.ncbi.nlm.nih.gov/pubmed/25730203

[17] Chavez-Alvarez S, Villarreal-Martinez A, Argenziano G, Ancer-Arellano J, Ocampo- Candiani J. Noodle pattern: a new dermoscopic pattern for crusted scabies (Norwegian scabies). J Eur Acad Dermatology Venereol [Internet]. 2017 Aug 16 [cited 2018 Jan 19]; Available from: http://doi.wiley.com/10.1111/jdv.14498

[18] Sánchez-Borges M, González-Aveledo L, CaprilesHulett A, Caballero-Fonseca F. Scabies, crusted (Norwegian) scabies and the diagnosis of mite sensitisation. Allergol Immunopathol (Madr) [Internet]. 2017 Dec [cited 2018 Jan 24]; Available from: http://linkinghub.elsevier.com/retrieve/pii/S03010546173 0099X

[19] Mollison LC, Lo STH, Marking G. HTLV-I and scabies in Australian Aborigines. Vol. 341, The Lancet. 1993. p. 1281-2. 